\title{
Sulfur-linked cyanobiphenyl-based liquid crystal dimers and the twist- bend nematic phase
}

Ewan Cruickshank ${ }^{\mathrm{a}}$, Mirosław Salamończyk ${ }^{\mathrm{b}, \mathrm{c}}$, Damian Pociecha ${ }^{\mathrm{b}}$, Grant J Strachan ${ }^{\mathrm{a}}$, John MD Storey ${ }^{\mathrm{a}}$, Cheng Wang ${ }^{\mathrm{c}}$, Jun Feng ${ }^{\mathrm{c}}$, Chenhui Zhu ${ }^{\mathrm{c}}$, Ewa Gorecka ${ }^{\mathrm{b}}$ and Corrie T Imrie ${ }^{\mathrm{a}}$

a. Department of Chemistry, School of Natural and Computing Sciences, University of Aberdeen, AB24 3UE Scotland, United Kingdom;

b. University of Warsaw, Faculty of Chemistry, ul. Zwirki i Wigury 101, 02-089, Warsaw, Poland

c. Lawrence Berkeley National Laboratory, Advanced Light Source, 1 Cyclotron Rd, Berkeley, CA 94720, USA

E-mail: c.t.imrie@abdn.ac.uk 


\begin{abstract}
The synthesis and characterisation of two series of cyanobiphenyl-based liquid crystal dimers containing sulfur links between the spacer and mesogenic units, the 4',4"-[1, $\omega$ alkanediylbis(thio)]bis-[1,1'-biphenyl]-4-carbonitriles $\quad(\mathrm{CBS} n \mathrm{SCB}), \quad$ and $\quad 4 '-\left(\left\{\omega-\left[\left(4^{\prime}-\right.\right.\right.\right.$ cyano[1,1'-biphenyl]-4-yl)oxy]alkyl\}thio)[1,1'-biphenyl]-4-carbonitriles (CBSnOCB), are described. The odd members of both series show twist-bend nematic and nematic phases whereas the even members exhibit only the nematic phase. An analogous cyanoterphenylbased dimer, $3^{4}-\left\{6\right.$-[(4'-cyano[1, $1^{\prime}$-biphenyl]-4-yl)thio]-hexyl $\}\left[1^{1}, 2^{1}: 2^{4}, 3^{1}\right.$-terphenyl $]-1^{4}$ carbonitrile (CT6SCB), is also reported and shows enantiotropic $\mathrm{N}_{\mathrm{TB}}$ and $\mathrm{N}$ phases. The transitional properties of these dimers are discussed in terms of molecular curvature, flexibility and biaxiality. The same molecular factors influence also birefringence of nematic phases. Resonant X-ray scattering studies of twist-bend nematic phase at both the carbon and sulfur absorption edges were performed, which allowed for determination of critical behaviour of helical pitch at the transition to nematic phase, the behaviour was found independent on molecular structure. It was also observed that despite the different molecular bending angle and flexibility, in all compounds the helical pitch length far from the $\mathrm{N}-\mathrm{N}_{\mathrm{TB}}$ transition corresponds to 4 longitudinal molecular distances.
\end{abstract}




\section{Introduction}

The twist-bend nematic phase, $\mathrm{N}_{\mathrm{TB}}$, is a rare example of a chiral structure made from achiral molecules and the first example of a chiral symmetry breaking in a system with no long-range positional order[1-4]. In the $\mathrm{N}_{\text {TB }}$ phase, the director forms a conical helix in which it is tilted with respect to the helical axis with doubly degenerate domains of opposite handedness. The pitch length in the $\mathrm{N}_{\text {TB }}$ phase is remarkably short, just a few molecular lengths. Prior to its experimental observation[1], the $\mathrm{N}_{\mathrm{TB}}$ phase had been predicted independently by Meyer[5] and Dozov[6] by considering differing molecular origins for the director modulation, either flexoelectric couplings or a negative bend elastic constant $\left(\mathrm{K}_{33}\right)$, respectively. Dozov proposed that bent molecules have a strong natural tendency to pack into bent structures but pure uniform bend in nature is not allowed and so must be accompanied by other deformations of the local director, either splay or twist, giving rise to either the splay-bend or twist bend nematic phases[6]. The first experimental assignment of the $\mathrm{N}_{\mathrm{TB}}$ phase was made for CB7CB compound[1], a member of the $\mathrm{CB} n \mathrm{CB}$ series with $n=7$,

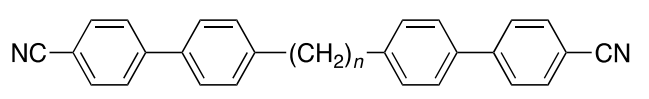

The material CB7CB is an example of a liquid crystal dimer in which two mesogenic units are linked through a flexible alkyl spacer[7, 8]. If the two mesogenic units are connected by an odd number of atoms then the average shape of the molecule is bent and hence a candidate to exhibit the $\mathrm{N}_{\text {TB }}$ phase within the framework of Dozov's prediction[6]. Indeed, prior to the unambiguous assignment of the $\mathrm{N}_{\mathrm{TB}}$ phase for $\mathrm{CB} 7 \mathrm{CB}[1,2]$, a nematic-nematic phase transition had been reported previously for other odd-membered dimers which, in hindsight, are examples of $\mathrm{N}_{\mathrm{TB}}-\mathrm{N}$ transitions [9, 10]. Dozov also predicted the existence of twist-bend smectic phases [6] and these have also recently been discovered [11, 12].

Although a range of different types of materials are now known to support the $\mathrm{N}_{\text {TB }}$ phase including rigid bent core mesogens [13], trimers and tetramers[14-17] and hydrogen bonded systems[18, 19], the overwhelming majority of twist-bend nematogens are composed of bent, odd-membered liquid crystal dimers (for recent examples[20-27]). Thus, molecular curvature is generally considered to be the critical structural feature that promotes the twist-bend nematic phase. This view has been reinforced by a generalised Maier-Saupe theory developed for rigid V-shaped molecules that has shown the twist-bend nematic - nematic phase transition 
temperature to be highly sensitive to the molecular bend angle[28]. Within the framework of this model, for bend angles less than $130^{\circ}$ only the $\mathrm{N}_{\mathrm{TB}}$ phase is observed, between $130^{\circ}$ and $150^{\circ}$ both $\mathrm{N}$ and $\mathrm{N}_{\text {TB }}$ phases are seen whereas above $150^{\circ}$ the $\mathrm{N}_{\mathrm{TB}}-\mathrm{N}$ transition is predicted only at very low temperatures $\left(\mathrm{T}_{\mathrm{NI}} / \mathrm{T}_{\mathrm{N}_{\mathrm{TB}}}{ }>2\right)$. Indeed, this approach underpinned the successful design of the first pure material to exhibit a direct $\mathrm{N}_{\mathrm{TB}}-\mathrm{I}$ transition[29], and such transitions remain rare[22]. The nematic phase preceding a twist-bend nematic phase shows anomalously low values of the bend elastic constant, $\mathrm{K}_{33}$, allowing for the appearance of an instantaneous, local heliconical structure[30] and may be exploited in new effects such as the electrically controlled selective reflection of light[31] and electrically tuneable lasers[32].

Despite intensive research, many properties of the $\mathrm{N}_{\mathrm{TB}}$ phase and how these relate to molecular structure have still to be established and understood. Of particular interest is the role of molecular curvature in driving the formation of the $\mathrm{N}_{\mathrm{TB}}$ phase and a key molecular feature that determines this is the nature of the linking group between the mesogenic units and spacer. Here we report dimers containing thioether linking groups, the 4',4"-[1, $\omega$-alkanediylbis(thio)]bis-[1,1'-biphenyl]-4-carbonitriles,

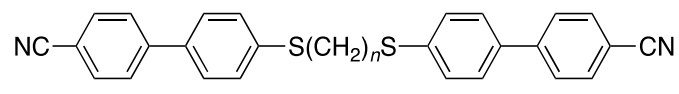

and refer to them using the acronym $\mathrm{CBS} n \mathrm{SCB}$ in which $\mathrm{CB}$ refers to cyanobiphenyl, $\mathrm{S}$ the thioether link, and $n$ the number of methylene units in the flexible spacer. Not only will the thioether link change the molecular curvature of these dimers, but also from an applications point of view, the introduction of the highly polarisable sulfur atoms is expected to increase their birefringence. We compare the properties of the CBSnSCB series with those of the corresponding methylene-linked dimers, the $\mathrm{CB} n \mathrm{CB}$ series[24] and the ether-linked $\mathrm{CBO} n \mathrm{OCB}$ dimers [33, 34].

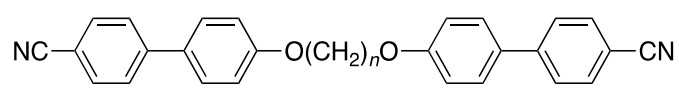

We also report the behaviour of the non-symmetric dimers containing thioether and

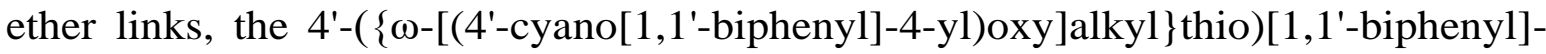
4-carbonitriles,

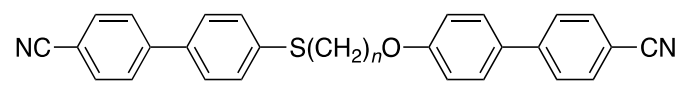


and by analogy refer to these using the acronym CBSnOCB. During the preparation of this paper, we became aware of a similar study reporting the transitional properties of members of the $\mathrm{CBS} n \mathrm{SCB}$ and $\mathrm{CBS} n \mathrm{OCB}$ series and there is good agreement between the data [35].

The dimer containing a cyanoterphenyl-based mesogenic unit $3^{4}-\left\{6-\left[\left(4^{\prime}-c y a n o\left[1,1^{\prime}-\right.\right.\right.\right.$ biphenyl]-4-yl)thio]-hexyl $\}\left[1^{1}, 2^{1}: 2^{4}, 3^{1}\right.$-terphenyl $]-1^{4}$-carbonitrile,

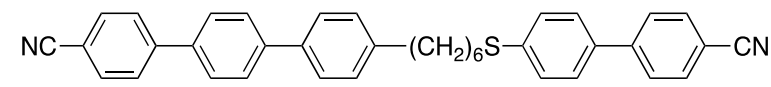

was also studied, and referred to using the acronym CT6SCB. This was selected as it is well known that the additional phenyl unit normally leads to broader temperature ranges of liquid crystal phases. The behaviour of CT6SCB is compared to that of CT7CB,

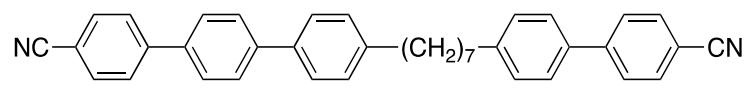

and $\mathrm{CTO} 6 \mathrm{CB}$,

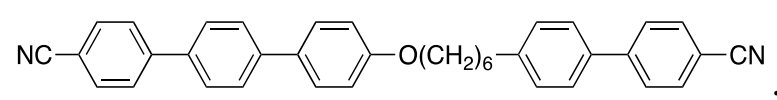

\section{Experimental}

\section{Synthesis}

The synthetic routes used to prepare the $\mathrm{CBS} n \mathrm{SCB}$ and $\mathrm{CBS} n \mathrm{OCB}$ series, and CT6SCB are shown in Schemes 1, 2 and 3, respectively. Detailed descriptions of the syntheses and the structural characterisation data for all the intermediates and final products are given in the Supplementary Information.

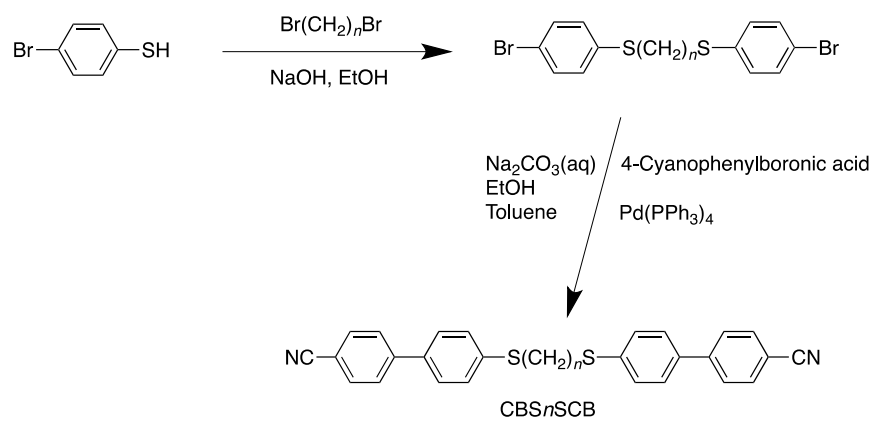

Scheme 1. Synthetic route used to prepare the CBSnSCB series. 


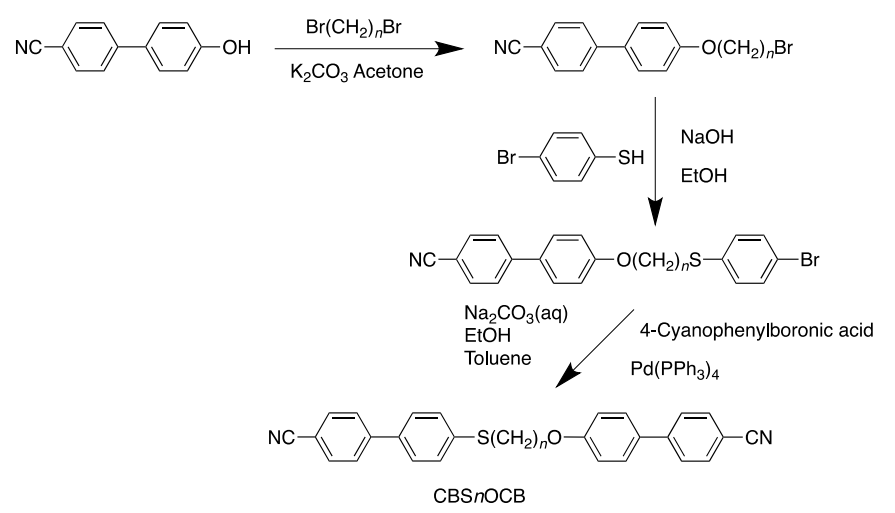

Scheme 2. Synthetic route used to prepare the CBSnOCB series.

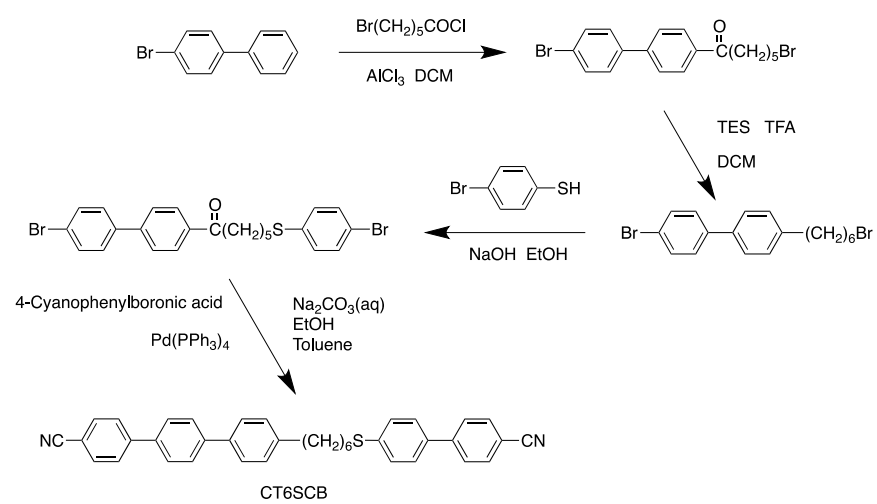

Scheme 3. Synthetic route used to prepare CT6SCB.

\section{Thermal Characterisation}

The phase behaviour of the dimers was studied by differential scanning calorimetry using a Mettler-Toledo DSC820 fitted with an intracooler and calibrated using indium and zinc as standards. Heating and cooling rates were $10^{\circ} \mathrm{C} \mathrm{min}^{-1}$ and all samples were measured under a nitrogen atmosphere. Transition temperatures and associated enthalpy changes were extracted from the second heating trace unless otherwise noted. For each sample, two aliquots were measured and the data listed are the average of the two sets of data. Phase characterisation was performed using polarised light microscopy using either an Olympus BH2 polarising light microscope equipped with a Linkam TMS 92 hot stage, or an Imager A2m polarizing microscope equipped with a Linkam heating stage. 


\section{Phase Diagrams}

To construct phase diagrams in order to confirm phase assignments or to determine virtual transition temperatures, binary mixtures of dimers were prepared by codissolving pre-weighed amounts in chloroform, and allowing the solvent to evaporate slowly at room temperature. Each mixture was further dried in a vacuum oven at $50^{\circ} \mathrm{C}$ overnight.

\section{Molecular Modelling}

In order to establish the geometric parameters of the dimers, quantum mechanical density functional theory was used[36]. Geometry optimization for sulfur-linked dimers with the spacer in the all-trans conformation was performed using Gaussian G09W at the B3LYP/6-311G(d,p) level of theory. For the sulfur-linked materials, this all-trans conformation was found to be lowest in energy. Comparison of the results of optimization of the methylene- and ether-linked dimers at the B3LYP/6$311 \mathrm{G}(\mathrm{d}, \mathrm{p})$ and the 6-31G(d) levels showed no discernible difference in the geometries found, and so optimization of the methylene- and ether-linked dimers was carried out at the B3LYP/6-31G(d) level. The all-trans conformations of the etherlinked dimers were selected even though calculations for similar sets of dimers of identical spacer length have shown that in the ground state the spacers contain a gauche defect about the O-C-C-C dihedral $\left(\approx \pm 62^{\circ}\right)[37-40]$. The difference in energy between the calculated ground state and all-trans conformations is small, typically around $1 \mathrm{~kJ} \mathrm{~mol}^{-1}$, and is likely to be substantially different in an ordered liquid crystal phase which will preferentially select more linear conformations [41]. Thus, we consider the all-trans conformation to be a better representation of the average molecular shape in discussing the transitional properties of the dimers containing ether links. Visualization of space-filling models of the output post-optimization was performed using QuteMol[42].

\section{X-ray Diffraction}

The X-ray diffraction studies were performed with the Bruker D8 GADDS system $(\mathrm{Cu} \mathrm{K} \alpha$ radiation, Goebel mirror, point beam collimator, Vantec2000 area detector). The resonant X-ray experiments on the liquid crystal materials were performed on the soft X-ray scattering beam line (11.0.1.2) at the Advanced Light Source of 
Lawrence Berkeley National Laboratory[43]. The X-ray beam was tuned to the Kedge of carbon absorption with the energy $\sim 284 \mathrm{eV}$. The X-ray beam with a crosssection of $300 \times 200 \mu \mathrm{m}$ was linearly polarized, with the polarization direction that can be continuously changed from the horizontal to vertical. Samples with thickness less than $1 \mu \mathrm{m}$ were placed between two 100 -nm-thick $\mathrm{Si}_{3} \mathrm{~N}_{4}$ slides (Norcada Inc.), for the measurements they were kept in vacuum to reduce attenuation of the soft $\mathrm{x}$ ray beam by air. The scattering intensity was recorded using the Princeton PI-MTE CCD detector, cooled to $-45^{\circ} \mathrm{C}$, having a pixel size of $27 \mu \mathrm{m}$, with an adjustable distance from the sample. The detector can be translated off axis, perpendicular to the X-ray beam direction, to collect the diffracted X-ray intensity at larger scattering angles. The adjustable position of the detector allowed the measurement of a broad range of $q$ vectors, corresponding to periodicities from approximately 5.0 to $500 \mathrm{~nm}$. The tender resonant X-ray scattering (TReXS) experiment was conducted at beamline 5.3.1 at the Advanced Light Source (ALS)[44]. The X-ray beam of energy $\sim 2470 \mathrm{eV}$ was focused to a circle spot with a diameter of $100 \square \mathrm{m}$ at the sample. The sample was mounted on a custom-made heating stage controlled by a Lake Shore 332 temperature controller with a K-type thermocouple, and kept in helium atmosphere. Samples of thickness about 10 m were placed between two 100-nmthick $\mathrm{Si}_{3} \mathrm{~N}_{4}$ slides (Norcada Inc.). The scattering intensity was recorded using a twodimension detector Plautus 300k (Dectris); the distance from the sample to detector was calibrated with silver behenate.

\section{Birefringence measurements}

Birefringence was measured with a setup based on a photoelastic modulator (PEM90, Hinds) working at a modulation frequency $\mathrm{f}=50 \mathrm{kHz}$; as a light source a halogen lamp (Hamamatsu LC8) was used equipped with a narrow bandpass filters (633 nm and $690 \mathrm{~nm}$ ). The signal from a photodiode (FLC Electronics PIN-20) was deconvoluted with a lock-in amplifier (EG\&G 7265) into $1 \mathrm{f}$ and $2 \mathrm{f}$ components to yield a retardation induced by the sample. Knowing the sample thickness, the retardation was recalculated into optical birefringence.

\section{Results and Discussion}

The transitional properties of the CBSnSCB series are listed in Table 1, and the odd homologues, with exception of the shortest $(n=1)$ and longest $(n=11)$ members, show the $\mathrm{N}_{\mathrm{TB}}-\mathrm{N}-\mathrm{I}$ phase sequence. The $\mathrm{N}$ phase was assigned on the basis of the 
observation of a schlieren texture containing both two and four brush point singularities and which flashed when subjected to mechanical stress, see Figure 1(a). The N-N $\mathrm{N}_{\mathrm{TB}}$ phase transition was identified in optical studies as a sudden suppression of director fluctuations ('flickering'), additionally a blocky schlieren texture developed when the sample was sandwiched between untreated glass slides, see Figure 1(b), and a characteristic striped texture was seen a few degrees below the transition in a planar cells. CBS1SCB melted directly into the isotropic phase and no liquid crystallinity was observed on cooling. CBS11SCB shows a conventional enantiotropic nematic phase but on cooling it crystallised without the observation of an additional liquid crystalline phase. In order to estimate the virtual transition temperatures for these dimers, the phase diagrams for binary mixtures with $\mathrm{CB} 7 \mathrm{CB}$ were constructed (Figures SI1 and SI2), and the values obtained are listed in Table 1. We note that for CBS1SCB these should be treated with some degree of caution given the extent of the extrapolation required on the phase diagram (Figure SI1).

Table 1. The transition temperatures (in ${ }^{\circ} \mathrm{C}$ ) and associated entropy changes scaled by gas constant for the $\mathrm{CBS} n \mathrm{SCB}$ series.

$\begin{array}{ccccccc}n & \mathrm{~T}_{\mathrm{Cr}-} /{ }^{\circ} \mathrm{C} & \mathrm{T}_{\mathrm{N}_{\mathrm{TB}} \mathrm{N} /} /{ }^{\circ} \mathrm{C} & \mathrm{T}_{\mathrm{NI}} /{ }^{\circ} \mathrm{C} & \Delta \mathrm{S}_{\mathrm{Cr}} / \mathrm{R} & \Delta \mathrm{S}_{\mathrm{N}_{\mathrm{TB}} \mathrm{N}} / \mathrm{R} & \Delta \mathrm{S}_{\mathrm{N}} / \mathrm{R} \\ 1 & 187 & { }^{\mathrm{a}} 24 & { }^{\mathrm{a}} 65 & 12.7 & - & - \\ 3 & 139 & 39 & 79 & 10.9 & 0.03 & 0.11 \\ 4 & 209 & - & { }^{\mathrm{b}} 169 & 11.5 & - & \mathrm{c}_{-} \\ 5 & 147 & 76 & 106 & 12.0 & 0.03 & 0.19 \\ 6 & 190 & - & { }^{\mathrm{b}} 162 & 12.7 & - & { }_{-} \\ 7 & 109 & 85 & 116 & 7.4 & 0.03 & 0.33 \\ 9 & 94 & 89 & 118 & 11.2 & - & 0.50 \\ 11 & 108 & { }^{\mathrm{a}} 88 & 116 & 14.0 & - & 0.65\end{array}$

${ }^{\text {a}}$ Virtual transition temperatures estimated from binary phase diagram with CB7CB. ${ }^{b}$ Measured using the polarised light microscope. ${ }^{c}$ Crystallisation precluded the measurement of the nematic-isotropic enthalpy. 


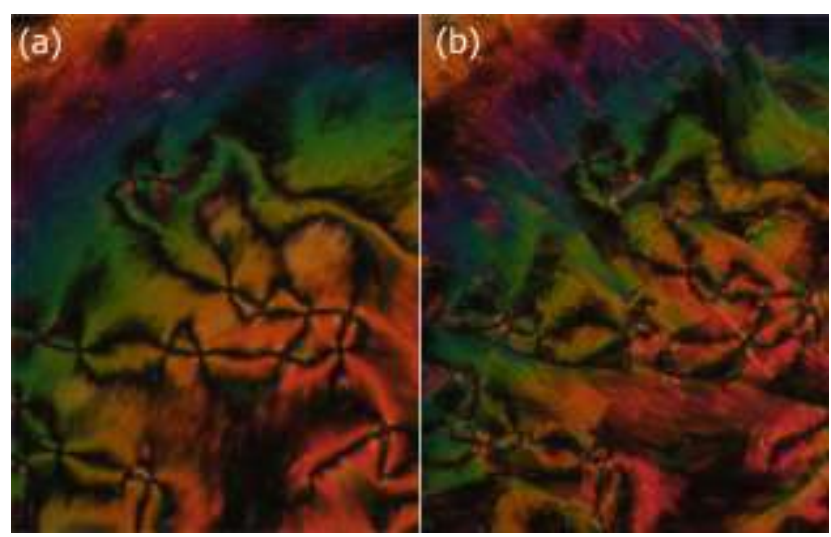

Figure 1. (a) Schlieren texture seen in the $\mathrm{N}$ phase $\left(\mathrm{T}=96^{\circ} \mathrm{C}\right)$ and (b) blocky schlieren texture observed in the $\mathrm{N}_{\mathrm{TB}}$ phase $\left(\mathrm{T}=70^{\circ} \mathrm{C}\right)$ for $\mathrm{CBS} 5 \mathrm{SCB}$.

The $\mathrm{N}_{\mathrm{TB}}$ phase assignment for this series was further confirmed by a miscibility study using CBS5SCB and CB7CB which revealed complete miscibility of the $\mathrm{N}_{\mathrm{TB}}$ phase across the whole composition range (Figure SI3). The even members, CBS4SCB and CBS6SCB, exhibited only a monotropic conventional nematic phase identified by the observation of a characteristic schlieren texture. Table 2 lists the transitional properties of several members of the $\mathrm{CBS} n \mathrm{OCB}$ series, and all exhibit a conventional nematic phase. In addition, CBS5OCB, CBS7OCB and CBS9OCB show a twist-bend nematic phase, while virtual twist-bend nematic to nematic phase transition temperatures have been estimated for CBS3OCB and CBS11OCB using phase diagrams (Figures SI4 and SI5). The even member CBS6OCB shows only a conventional monotropic nematic phase. Enantiotropic $\mathrm{N}_{\mathrm{TB}}$ and $\mathrm{N}$ phases are seen for CT6SCB, see Figure 2, with transition temperatures: $\mathrm{Cr} 132^{\circ} \mathrm{C} \mathrm{N} \mathrm{N}_{\mathrm{TB}} 144^{\circ} \mathrm{C} \mathrm{N} 238^{\circ} \mathrm{C} \mathrm{I}$ and the associated entropy changes $(\Delta \mathrm{S} / \mathrm{R})$ are $5.6, \approx 0$ and 0.35 , respectively. For all studied $\mathrm{CBS} n \mathrm{SCB}, \mathrm{CBS} n \mathrm{OCB}$ and $\mathrm{CT} 6 \mathrm{SCB}$ compounds, in non-resonant X-ray patterns a diffuse signal was detected for both the $\mathrm{N}$ and $\mathrm{N}_{\text {TB }}$ phases in the low angle region consistent with a lack of long-range positional order, and corresponding to half the molecular length, indicating a locally intercalated molecular structure. The CBSnSCB dimers show a large alternation in their nematic-isotropic transition temperatures, $\mathrm{T}_{\mathrm{NI}}$, on varying the length and parity of the spacer (Figure $3 \mathrm{a}$ ). This is archetypal behaviour for liquid crystal dimers attributed to the dependence of the overall molecular shape on the parity of the spacer when considered in the all-trans conformation $[7,8]$. Thus, for an even-membered homologue the mesogenic groups are parallel whereas in an odd-membered dimer they are inclined, see Figures 4 and 5 , respectively. The more linear structure of an even-membered dimer is more 
compatible with the molecular organisation found in the nematic phase resulting in, for example, higher values of $\mathrm{T}_{\mathrm{NI}}$. Figure 3(a) compares the values of $\mathrm{T}_{\mathrm{NI}}$ for members of the $\mathrm{CBS} n \mathrm{SCB}, \mathrm{CB} n \mathrm{CB}$ and $\mathrm{CBO} n \mathrm{OCB}$ series.

Table 2. The transition temperatures (in ${ }^{\circ} \mathrm{C}$ ) and associated entropy changes scaled by gas constant for the $\mathrm{CBS} n \mathrm{OCB}$ series.

$\begin{array}{cccccc}n & \mathrm{~T}_{\mathrm{Cr}} /{ }^{\circ} \mathrm{C} & \mathrm{T}_{\mathrm{N}_{\mathrm{TB}} \mathrm{N}} /{ }^{\circ} \mathrm{C} & \mathrm{T}_{\mathrm{NI}} /{ }^{\circ} \mathrm{C} & \Delta \mathrm{S}_{\mathrm{Cr}} / \mathrm{R} & \Delta \mathrm{S}_{\mathrm{NI}} / \mathrm{R} \\ 3 & 141 & { }^{\mathrm{a}} 78 & 138 & 8.2 & 0.30 \\ 5 & 127 & 81 & 140 & 4.5 & 0.48 \\ 6 & 185 & & 184 & 8.4 & 1.05 \\ 7 & 118 & 88 & 149 & 6.3 & 0.57 \\ 9 & 104 & 85 & 143 & 7.1 & 0.71 \\ 11 & 114 & { }^{\mathrm{a} 91} & 137 & 12.6 & 0.83\end{array}$

${ }^{a}$ Virtual transition temperatures estimated from binary phase diagram with CB7CB.

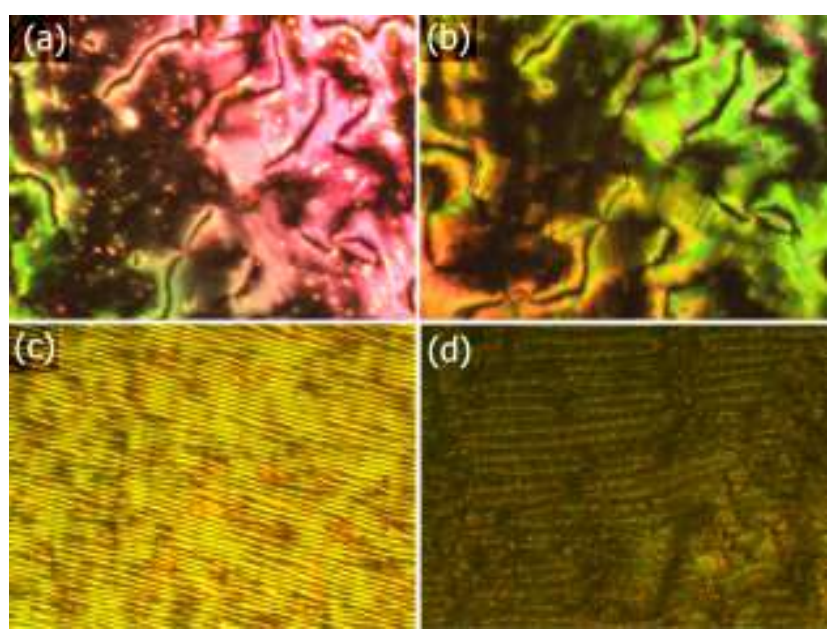

Figure 2. Textures observed for CT6SCB: (a) the schlieren texture of the nematic phase $\left(\mathrm{T}=189^{\circ} \mathrm{C}\right)$; (b) the blocky schlieren texture $\left(\mathrm{T}=126^{\circ} \mathrm{C}\right)$, (c) the stripe texture $\left(\mathrm{T}=116^{\circ} \mathrm{C}\right)$ and $(\mathrm{d})$ the rope-like texture $\left(\mathrm{T}=109^{\circ} \mathrm{C}\right)$ of the twist-bend nematic phase. 

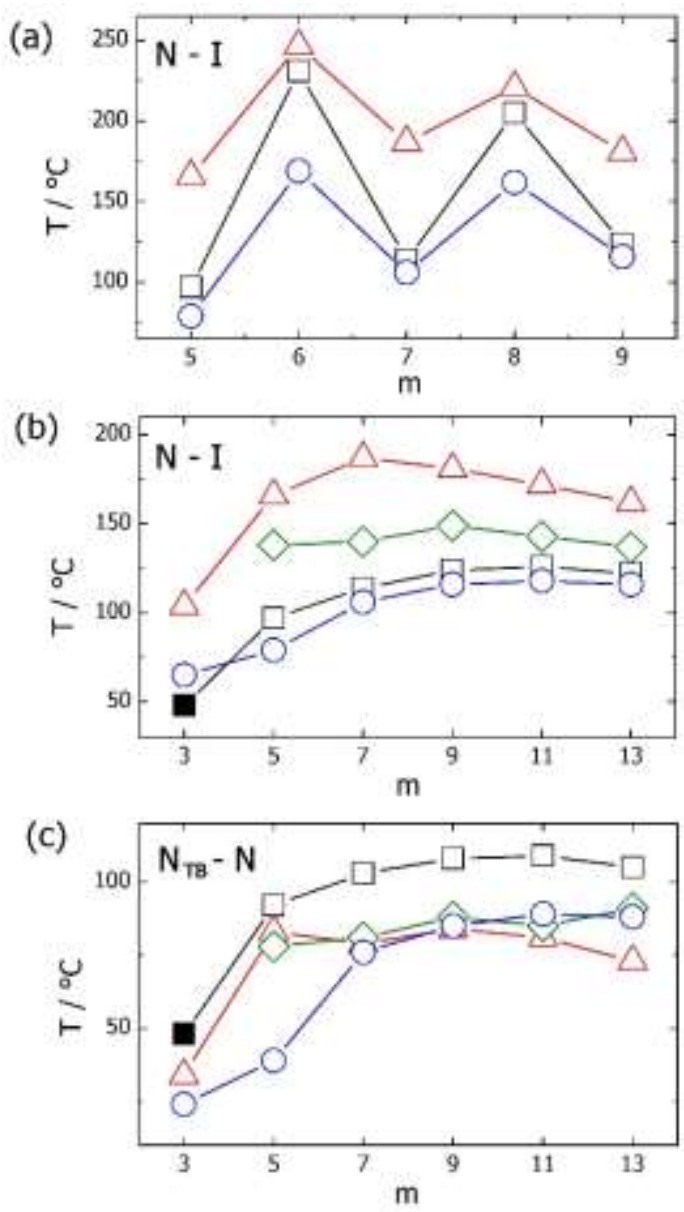

Figure 3 Transition temperatures for the $\mathrm{CBS} n \mathrm{SCB}$ (blue circles), $\mathrm{CB} n \mathrm{CB}$ (black squares), $\mathrm{CBO} n \mathrm{OCB}$ (red triangles) and $\mathrm{CBS} n \mathrm{OCB}$ (green diamonds) series. The temperatures are plotted as a function of the total number of atoms, $m$, linking the two cyanobiphenyl units such that for $\mathrm{CB} n \mathrm{CB} m=n$, whereas for $\mathrm{CBS} n \mathrm{SCB}, \mathrm{CBO} n \mathrm{OCB}$ and $\mathrm{CBS} n \mathrm{OCB} \mathrm{m}=n+2$. (a) Dependence of the nematic-isotropic transition temperatures on the number of atoms, $m$, in the spacer; (b) the N-I and (c) the $\mathrm{N}_{\mathrm{TB}}-\mathrm{N}$ transition temperatures of the odd homologues; the filled symbol represents a $\mathrm{N}_{\mathrm{TB}}-\mathrm{I}$ transition.

To make meaningful comparisons between these series we must compare dimers having the same number of atoms joining the two mesogenic units, and thus values of $\mathrm{T}_{\mathrm{NI}}$ for $\mathrm{CBS} n \mathrm{SCB}$ and $\mathrm{CBO} n \mathrm{OCB}$ are compared with those for $\mathrm{CB}(n+2) \mathrm{CB}$. The $\mathrm{CBO} n \mathrm{OCB}$ series show the highest values of $\mathrm{T}_{\mathrm{NI}}$ and the CBSnSCB dimers the lowest. The $\mathrm{CB} n \mathrm{CB}$ dimers show intermediate values of $\mathrm{T}_{\mathrm{NI}}$; even members have values slightly less than the even $\mathrm{CBO}$ OCB dimers but much higher than CBSnSCB, whereas the odd members show $\mathrm{T}_{\mathrm{NI}} \mathrm{S}$ slightly higher than the CBSnSCB dimers and much lower than the $\mathrm{CBO} n \mathrm{OCB}$ series. Thus, the size of the alternation in $\mathrm{T}_{\mathrm{NI}}$ is greatest for the $\mathrm{CB} n \mathrm{CB}$ series. Luckhurst and his co-workers have shown 
that the differences in the values of $\mathrm{T}_{\mathrm{NI}}$, and the associated scaled entropy change, $\Delta \mathrm{S}_{\mathrm{NI}} / \mathrm{R}$, for the $\mathrm{CB} n \mathrm{CB}$ and $\mathrm{CBO} n \mathrm{OCB}$ series may be accounted for in terms of molecular geometry, and specifically, the bond angle between the para-axis of the mesogen and the first bond in the spacer[45, 46]. In these studies the bond angle of the methylene link is set to $113.5^{\circ}$ and for an ether link $126.4^{\circ}$. Our DFT calculations agree well the former value but suggest an angle of around $119^{\circ}$ for the latter.

(a)

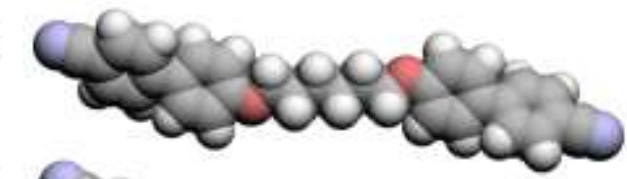

(b)

(c)

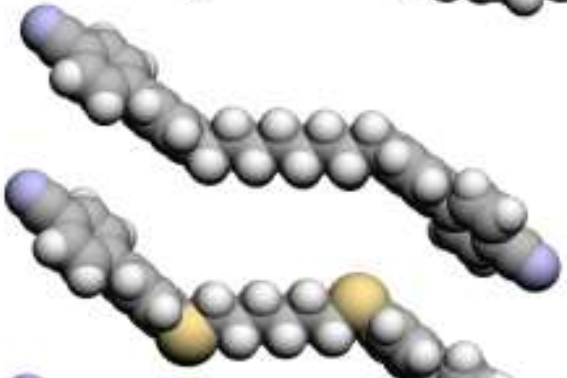

(d)

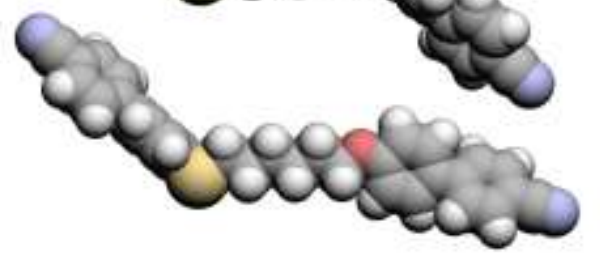

Figure 4. Space filling models for even-member dimers (a) CBO6OCB, (b) CB8CB, (c) CBS6SCB and (d) CBS6OCB. In each, the spacer is in the all-trans conformation.

(a)

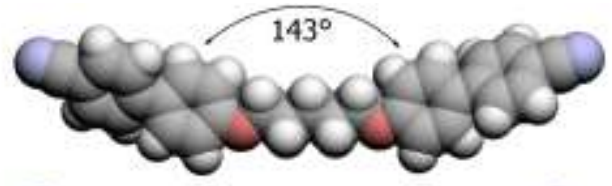

(b)

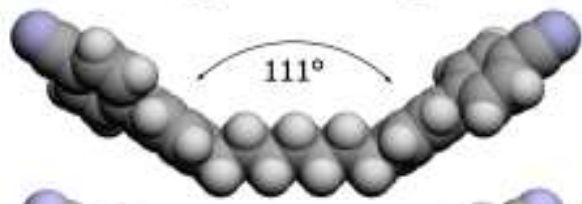

(c)

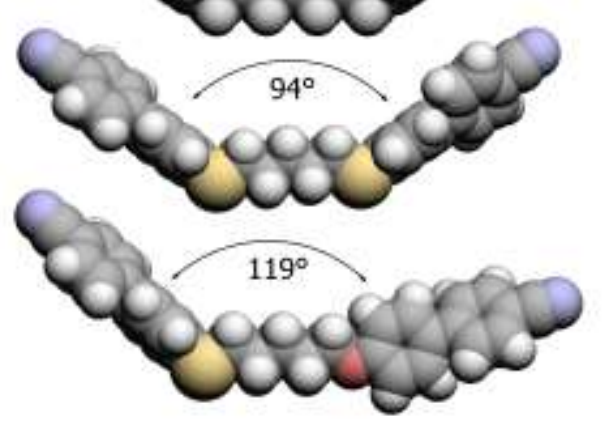

Figure 5. Space filling models for odd-member dimers (a) CBO5OCB, (b) CB7CB, (c) CBS5SCB and (d) CBS5OCB. In each, the spacer is in the all-trans conformation. 
This bond angle has a major effect on the overall molecular shape of odd-members such that an odd-membered ether-linked dimer is more linear than the corresponding methylene-linked material, see Figures 5(a, b). To a first approximation this difference in curvature can be estimated by the angle subtended by the two nitrile bonds in each compound. Thus, for CBO5OCB the bend angle is $143^{\circ}$ compared to $111^{\circ}$ for $\mathrm{CB} 7 \mathrm{CB}$. The greater shape anisotropy of the ether-linked dimer gives rise to higher values of $\mathrm{T}_{\mathrm{NI}}$. In contrast the molecular shape of an even-membered dimer is considered to be relatively insensitive to changes in this bond angle as the mesogenic cores remain essentially parallel in the all-trans conformations irrespective of the bond angle, see Figures $4(\mathrm{a}, \mathrm{b})$, and the values of $\mathrm{T}_{\mathrm{NI}}$ are predicted to be rather similar. Thus, as this bond angle decreases the size of the alternation in $\mathrm{T}_{\mathrm{NI}}$ on varying the parity of the spacer is predicted to increase. Furthermore, this model based solely on geometrical factors, predicted that for an odd-membered dimer, replacing the oxygen links by methylene groups will reduce $\Delta \mathrm{S}_{\mathrm{NI}} / \mathrm{R}$, whereas for an even spacer it increases[45]. The model has successfully accounted for the transitional properties not only of the $\mathrm{CB} n \mathrm{CB}$ and $\mathrm{CBO} n \mathrm{OCB}$ series[37] but also for a range of other methylene- and ether-linked dimers having different mesogenic units[47-49]. For the CBSnSCB dimers the bond angle between the para-axis of the mesogen and the first bond in the spacer is calculated to be about $100.5^{\circ}$, significantly less than the $113.5^{\circ}$ for $\mathrm{CB} n \mathrm{CB}$ dimers (Figure 5(c)). Thus, considerably lower values of $\mathrm{T}_{\mathrm{NI}}$ might be expected for the odd members of the CBSnSCB series than for the corresponding $\mathrm{CB} n \mathrm{CB}$ dimers but the observed values are, in fact, rather similar (Figure 3(b)). For even members, we have seen that $\mathrm{T}_{\mathrm{NI}}$ is significantly lower for the CBSnSCB dimers compared to the other series (Figure 3(a)) even though in each the mesogenic units are essentially parallel (Figure 4). A comparison of the $\mathrm{T}_{\mathrm{NIS}}$ for all the odd members of the three series (Figure 3(b)) reveals the $\mathrm{CBO}$ OCB dimers show the highest values of $\mathrm{T}_{\mathrm{NI}}$ for all spacer lengths consistent with their least bent molecular shape (Figure 5). The values of $\mathrm{T}_{\mathrm{NI}}$ for the $\mathrm{CBS} n \mathrm{SCB}$ and $\mathrm{CB} n \mathrm{CB}$ series are rather similar with the latter showing the higher temperatures. The estimated bend angle for CBS5SCB is $94^{\circ}$ and this much smaller bend angle seems inconsistent with the transitional behaviour. It would appear, therefore, that the transitional properties of both the even and odd members of the CBSnSCB series cannot be accounted for solely in terms of geometric factors relating to the bond angle between the para-axis of the mesogen and the first bond in the spacer. It is interesting to note that the odd-membered dimers are behaving in a 
similar fashion to the analogous conventional low molar mass mesogens such that $\mathrm{T}_{\mathrm{NI}}$ for $5 \mathrm{CB}$ and $4 \mathrm{SCB}$ are the same and $40 \mathrm{~K}$ lower than that of 4OCB [50].

We suggest that at least two other factors need to be considered to account for the transitional behaviour of the CBSnSCB series: the steric bulk associated with the sulfur atom, and the rotational barrier about the C-S bonds. For the even members, the increased size of the sulfur atom compared to either a methylene unit or an oxygen atom clearly changes the molecular shape profile (Figure 4). This is difficult to quantify but, for example, the breadth of the dimer estimated by the distance between planes containing the mesogenic units for CBO6OCB is $4.2 \AA$, increases to $5.9 \AA$ for $\mathrm{CB} 8 \mathrm{CB}$ and $7.4 \AA$ for CBS6SCB. It is known that even modest changes to the molecular biaxiality can give appreciable changes in transitional behaviour [51, 52], and the increased molecular biaxiality for CBS6SCB will reduce $\mathrm{T}_{\mathrm{NI}}$ as observed. This view is supported by the value of $\Delta \mathrm{S}_{\mathrm{NI}} / \mathrm{R}$ for CBS6SCB which is about half that seen for CBO6OCB. We also note that the DFT models suggest that the two cyanobiphenyl units in the CBSnSCB dimers are inclined by a small angle with respect to each other unlike their parallel disposition in the other two series. For the odd members the similarity in behaviour between the $\mathrm{CBS} n \mathrm{SCB}$ and $\mathrm{CB} n \mathrm{CB}$ series may be accounted for in terms of the lower rotational barrier around the phenyl-S [53] and $\mathrm{S}-\mathrm{CH}_{2}$ groups [54]. Thus, the nematic field can select more linear conformers at a lower energy cost than for the $\mathrm{CB} n \mathrm{CB}$ series, and a similar argument was used to account for the high transition temperatures seen for flexible polysiloxane-based side chain liquid crystal polymers $[55,56]$. This flexibility also serves to mitigate the enhanced molecular biaxiality arising from the inclusion of the larger sulfur atom. As the spacer length becomes shorter, the shapes of the molecules should become more different and the difference in $\mathrm{T}_{\mathrm{NI}}$ predicted to increase, as indeed it does for CB5CB and CBS3SCB. The rather similar values of $\Delta \mathrm{S}_{\mathrm{NI}} / \mathrm{R}$ seen for the two series are consistent with this interpretation of their transitional behaviour. An alternative view, however, may be argued to account for the data shown in Figures 3(a,b) such that a more flexible linkage allows for increasingly nonlinear conformations to be adopted which disrupt the nematic organisation, and reduce $\mathrm{T}_{\mathrm{NI}}[53,57-61]$. Such a view, although consistent with the behaviour of the even members of the series, appears inconsistent with the data shown for the odd members. The surprising inversion of the clearing temperatures for $\mathrm{CB} 3 \mathrm{CB}$ and CBS1SCB (Figure 3(b)) may be accounted for in terms of their molecular shapes (Figure 6). The interaction between the two sulfur atoms twists the molecule 
effectively making it more linear than CB3CB. Figure 3(b) also shows the values of $\mathrm{T}_{\mathrm{NI}}$ for the $\mathrm{CBS} n \mathrm{OCB}$ dimers and these are intermediate between those of the corresponding $\mathrm{CBS} n \mathrm{SCB}$ and $\mathrm{CBO} n \mathrm{OCB}$ dimers. For $n=5,7,9$, and 11, the $\mathrm{T}_{\mathrm{NIS}}$ of $\mathrm{CBS} n \mathrm{OCB}$ are similar to the geometric mean of those of the symmetric dimers. The notable exception is the $\mathrm{T}_{\mathrm{NI}}$ for $\mathrm{CBS} 3 \mathrm{OCB}$ being some $18 \mathrm{~K}$ higher than the geometric mean of the $\mathrm{T}_{\mathrm{NI}}$ for $\mathrm{CBS} 3 \mathrm{SCB}$ and $\mathrm{CBO} 3 \mathrm{OCB}$. This may be attributed to the increased molecular biaxiality arising from the sulfur atoms which suppresses $\mathrm{T}_{\mathrm{NI}}$ for CBS3SCB. The values of $\Delta \mathrm{S}_{\mathrm{NI}} / \mathrm{R}$ of the CBSnOCB dimers are higher than those of the corresponding $\mathrm{CBS} n \mathrm{SCB}$ materials reflecting the increased biaxiality of the latter. It is interesting to note that for the even membered CBS6OCB a reduction of 7 $\mathrm{K}$ in $\mathrm{T}_{\mathrm{NI}}$ is seen compared to the geometric mean of those of CBS6SCB and CBO6OCB, presumably reflecting that the mesogenic units are no longer parallel given the quite different angles associated with the two different linking groups (Figure 4). The twist-bend nematic-nematic transition temperatures, $\mathrm{T}_{\mathrm{N}_{\mathrm{TB}} \mathrm{N}}$, for the four series are compared in Figure 3(c). For all chain lengths the highest values of $\mathrm{T}_{\mathrm{N}_{\mathrm{TB}} \mathrm{N}}$ are seen for the $\mathrm{CB} n \mathrm{CB}$ series although the bend angle for the series, as defined earlier, is appreciably larger than for the CBSnSCB series. This highlights the shortcomings in describing molecular curvature in terms of a single bend angle and failing to capture the molecular biaxiality. The remaining series show rather similar values of $\mathrm{T}_{\mathrm{NB}_{\mathrm{T}}}$ across the chain lengths with the exception of CBS3SCB for which $\mathrm{T}_{\mathrm{N}_{\mathrm{TB}} \mathrm{N}}$ is surprisingly low. This is presumably associated with enhanced molecular biaxiality discussed earlier.

(a)
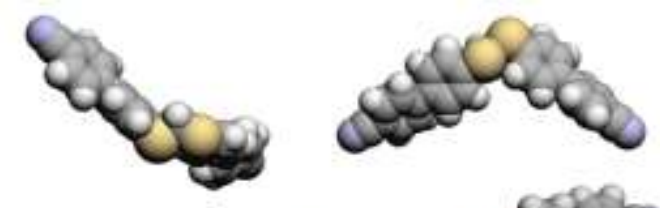

(b)

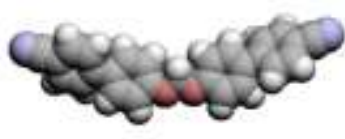

(c)
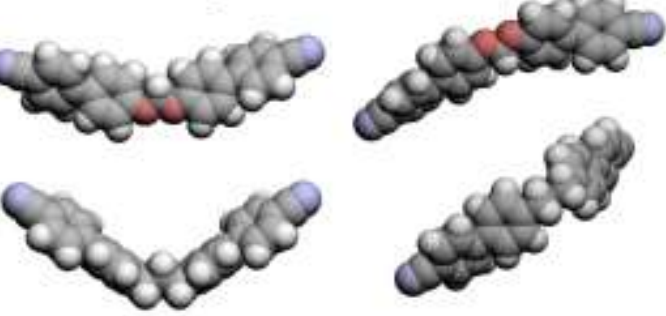

Figure 6. Space filling models shown from two differing perspectives for (a) CBS1SCB, (b) CBO1OCB, and (c) CB3CB. 
For more detailed studies of their physical properties, the materials with the broadest range of enantiotropic liquid crystal phases were chosen (Figure 7).

For all materials optical studies revealed that the birefringence increases in the nematic phase on cooling from the isotropic liquid following the critical dependence $\Delta \mathrm{n}=\Delta \mathrm{n}_{0}((\mathrm{~T}-\mathrm{Tc}) / \mathrm{Tc})^{\beta}{ }_{\text {with }}^{\mathrm{n}_{0}}$ being a hypothetical birefringence for a nematic phase with an ideal orientational order of the molecules (Figure 8). Interestingly, the measured birefringence departs from the critical dependence when approaching the $\mathrm{N}-\mathrm{N}_{\text {TB }}$ phase transition (Figure 8), such behaviour was attributed recently to the formation of instantaneous local heliconical states[30]. Among the dimers containing cyanoterphenyl (CT) unit, the highest $\square_{0}$ is found for the dimer with the methylene and ether linkages $\left(\mathrm{n}_{\mathrm{o}}=0.383\right.$ ), consistent with the most linear shape of CTO6CB molecules. Interestingly, for compound with methylene and thioether linkages the value of $\mathrm{n}_{\text {o }}$ was higher than for compound having only methylene linking groups, $\left(\mathrm{n}_{0}=0.378\right.$ and 0.325 for CT6SCB and CT7CB, respectively), although the latter has more linear molecules. A higher value of $\square_{b}$ for CTS6CB is due to the higher polarizability of the sulfur atom[62, 63]. For compounds containing two cyanobiphenyl units (CB-CB) the trend is similar - the birefringence of $\mathrm{CB} 6 \mathrm{OCB}$ is larger than for $\mathrm{CB} 7 \mathrm{CB}$, and that of $\mathrm{CBS5OCB}$ is larger than for CB6OCB (Figure 8).

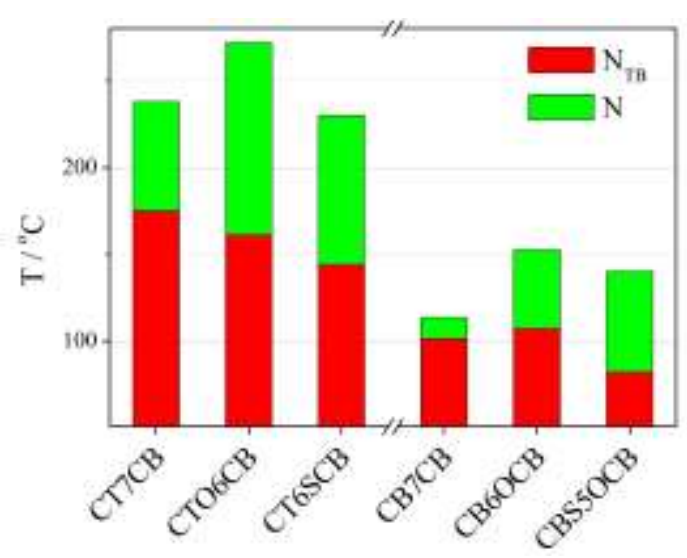

Figure 7. Transition temperatures for CT-CB and CB-CB dimers with different linking groups. 

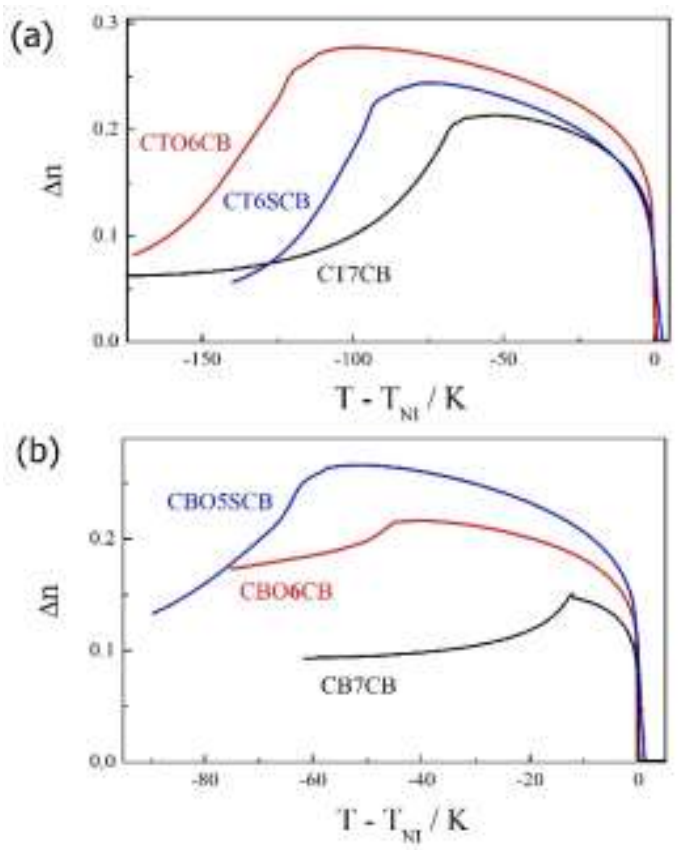

Figure 8. Birefringence as a function of temperature for (a) CT-CB and (b) CB-CB dimers.

In the $\mathrm{N}_{\mathrm{TB}}$ phase a decrease in birefringence is detected that is related to the tilting and averaging of the molecular positions around the helical axis[64]. The conical angle calculated from the decrease of the birefringence (Figure SI6) for all studied CT-CB materials is comparable, approaching $45-50^{\circ}$, and is independent of the nature of the linkages. For the CB-CB compounds, the tilt angle far from the N$\mathrm{N}_{\mathrm{TB}}$ phase transition is only slightly smaller, in the range $35-40^{\circ}$, except for CB6OCB for which it is $\sim 25^{\circ}$ (Figure SI6)

In recent reports it has been suggested that the helical pitch in the $\mathrm{N}_{\text {TB }}$ phase is driven by molecular shape, i.e., molecular bend. To verify this assumption the resonant X-ray scattering studies at carbon absorption edge (RSoXS) were performed for the chosen compounds, and in addition for molecules with a thioether linkage studies at the sulfur absorption edge (TReXS) were also completed. Such measurements, performed at the resonance condition, allow us to determine the periodic structures due to spatial modulations of molecular orientation, despite a lack of positional order. Both types of measurements gave qualitatively similar results; the helix in the $\mathrm{N}_{\text {TB }}$ phase appears through a first order transition with pronounced fluctuation of structure observed in the nematic phase (Figure 9 and Figure SI7). The helical pitch, $p$, decreases with decreasing temperature, and deep in the $\mathrm{N}_{\mathrm{TB}}$ phase it corresponds to several $\mathrm{nm}$. After comparing the data obtained from resonant X-ray 
measurements at the sulfur and carbon absorption edges (Figure 9), it is clear that the 'spreading' of the diffraction signal near the $\mathrm{N}_{\mathrm{TB}}-\mathrm{N}$ transition, observed by the RSoXS method, interpreted before as a 'softening of the structure' [4] is most probably an artefact caused by poor temperature homogeneity in the sample under the high vacuum required for measurements at the carbon resonance condition.
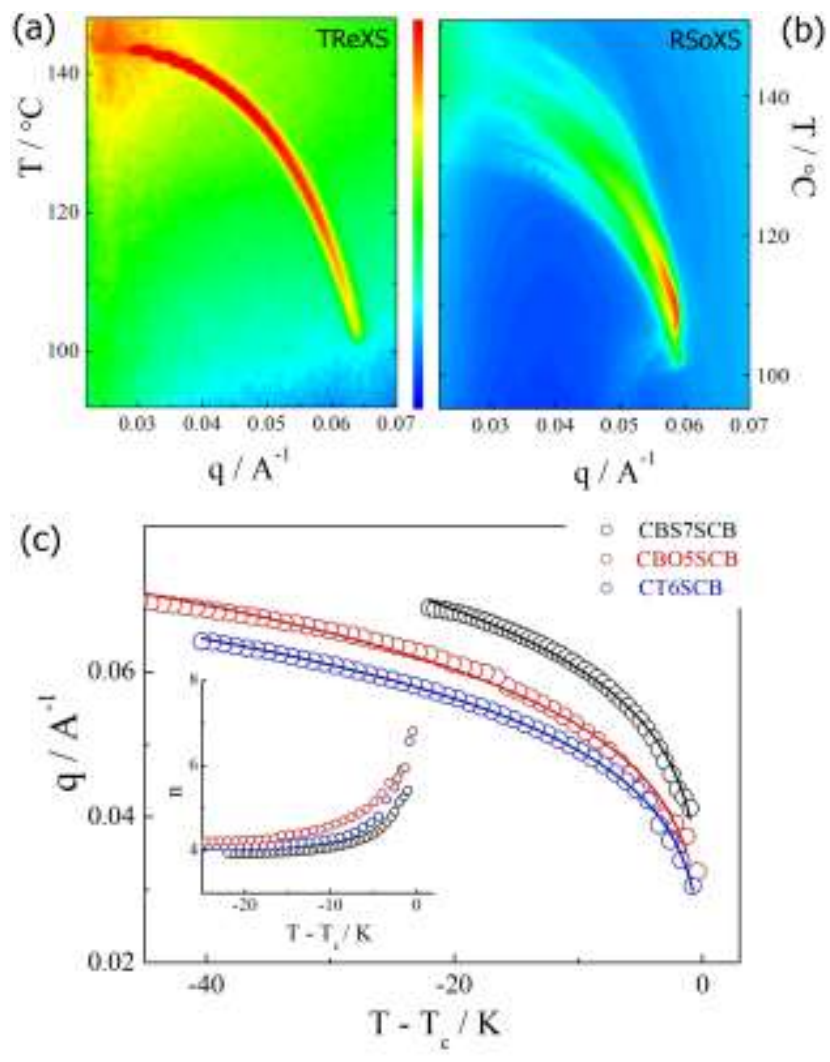

Figure 9. Temperature evolution of the magnitude of wavevector related to heliconical pitch in the $\mathrm{N}_{\mathrm{TB}}$ phase of CT6SCB dimer, obtained by (a) TReXS and (b) RSoXS measurements. (c) Temperature dependence of the helical pitch in CBS7SCB (black) $\mathrm{CBO} 5 \mathrm{SCB}$ (red) and $\mathrm{CT} 6 \mathrm{SCB}$ (blue). Lines show the fitting to power law dependence, with critical exponents $\sim 0.2$. In the inset the number of molecules per helix turn estimated as $n=\frac{2 \pi}{q \cos (\theta) L}$.

Therefore, only the data obtained from the TReXS method were analysed in details regarding critical behaviour. The magnitude of the wavevector of the helical structure, $\quad \mathrm{q}=2 \square \mathrm{p}, \quad$ shows critical temperature dependence, $\mathrm{q}=\mathrm{q}_{0}((\mathrm{~T}-\mathrm{Tc}) / \mathrm{Tc})^{\beta}$, it decreases on approaching the nematic phase, and for all the compounds studied the critical exponent $\square$ was close to 0.2. This critical increase of the pitch near the transition to the nematic phase can be a result of the 
temperature induced change of conical angle and/or the change of the number of molecules per turn. Based on optical studies, the $\mathrm{N}-\mathrm{N}_{\text {тв }}$ transition appears to be weakly first order with critical exponent for conical angle changes close to the mean field value 0.5 , therefore assuming that the increase of the pitch length near the $\mathrm{N}_{\mathrm{TB}^{-}}$ $\mathrm{N}$ phase transition is related only to conical angle changes, $\mathrm{p}=\mathrm{nL} \cos (\theta) \sim \mathrm{nL}(1-$ $\theta^{2}$ ), $L$ being the molecular length and $n$ number of molecules per turn, within the mean-field approximation we expect the critical exponent for the pitch to be close to -1 , clearly inconsistent with the experimentally determined value. The observed dependence suggests that upon approaching the transition to the nematic phase the number of molecules per turn, $n$, increases critically (inset in Figure 9c). Interestingly, far from the transition the number of molecules per turn is 4 for all studied compounds, although the bending angle and molecular flexibility varies, depending on the material studied.

\section{Conclusions}

We have compared the behaviour of several series of liquid crystal dimers, between which the chemical nature of the linking groups between the mesogenic units and spacer has been systematically varied to include methylene, ether and thioether units. For dimers containing an odd number of atoms in the spacer, the ether-linked are the most linear and the thioether-linked the most bent. This increasing molecular curvature decreases the nematic-isotropic transition temperature and also affects the birefringence of the nematic phase. Theories developed for rigid V-shaped molecules predict that the formation of the $\mathrm{N}_{\mathrm{TB}}$ phase and its stability is coupled to molecular curvature[28, 65]. Experimentally the $\mathrm{N}-\mathrm{N}_{\text {тв }}$ transition temperature is the highest for dimers containing a methylene spacer, and similar for the corresponding ether and thioether materials, although the thioether dimers are clearly more bent than their methylene counterparts. It appears that the optimal molecular curvature for the formation of the $\mathrm{N}_{\mathrm{TB}}$ phase is around $120^{\circ}$, as observed previously ${ }^{62}$. It should be noted, however, that the flexibility of these dimers varies considerably and how this impacts on the formation of the $\mathrm{N}_{\mathrm{TB}}$ phase is unclear. Surprisingly, despite the differing molecular structures, the helical pitch length, far from the $\mathrm{N}-\mathrm{N}_{\mathrm{TB}}$ transition, corresponds to 4 longitudinal molecular distances in all the materials studied. On approaching the transition to the nematic phase the pitch starts to unwind, and the number of molecules per turn increases in a critical fashion, with the $\mathrm{N}-\mathrm{N}_{\mathrm{TB}}$ 
transition being weakly first order. There is clearly much work both experimental and theoretical to be done to understand these fascinating systems.

\section{Conflicts of interest}

There are no conflicts to declare.

\section{Acknowledgements}

EG and DP acknowledge the support of the National Science Centre (Poland): (Grant Number 2016/22/A/ST5/00319). We acknowledge use of Beamline 5.3.1 and 11.0.1.2 of the Advanced Light Source supported by the Director of the Office of Science, Office of Basic Energy Science, of The U.S. Department of Energy under contract no. DE-AC02-05CH11231. We thank Alex Liebman-Pelaez for designing the heating stage used for TReXS measurement.

\section{Notes and references}

[1] Cestari M, Diez-Berart S, Dunmur DA, Ferrarini A, de la Fuente MR, Jackson DJB, Lopez DO, Luckhurst GR, Perez-Jubindo MA, Richardson RM, Salud J, Timimi BA, Zimmermann $\mathrm{H}$. Phase behavior and properties of the liquid-crystal dimer 1 ",7 "-bis(4-cyanobiphenyl-4 '- yl) heptane: A twist-bend nematic liquid crystal. Phys Rev E. 2011;84(3):031704.

[2] Borshch V, Kim YK, Xiang J, Gao M, Jakli A, Panov VP, Vij JK, Imrie CT, Tamba MG, Mehl GH, Lavrentovich OD. Nematic twist-bend phase with nanoscale modulation of molecular orientation. Nature Commun. 2013;4:2635.

[3] Chen D, Porada JH, Hooper JB, Klittnick A, Shen YQ, Tuchband MR, Korblova E, Bedrov D, Walba DM, Glaser MA, Maclennan JE, Clark NA. Chiral heliconical ground state of nanoscale pitch in a nematic liquid crystal of achiral molecular dimers. Proc Nat Acad Sci USA. 2013;110(40):15931-15936.

[4] Zhu CH, Tuchband MR, Young A, Shuai M, Scarbrough A, Walba DM, Maclennan JE, Wang C, Hexemer A, Clark NA. Resonant Carbon K-Edge Soft X-Ray Scattering from Lattice-Free Heliconical Molecular Ordering: Soft Dilative Elasticity of the Twist-Bend Liquid Crystal Phase. Phys Rev Lett. 2016;116(14):147803.

[5] Meyer R. In Structural problems in liquid crystal physics, Les Houches Summer School in Theoretical Physics 1973 Molecular Fluids; Balian R, Weil G, Eds. New York (NY): Gordon and Breach; 1976. p. 273-373.

[6] Dozov I. On the spontaneous symmetry breaking in the mesophases of achiral banana-shaped molecules. Europhys Lett. 2001;56(2):247-253.

[7] Imrie CT, Henderson PA. Liquid crystal dimers and higher oligomers: Between monomers and polymers. Chem Soc Rev. 2007;36(12):2096-2124.

[8] Imrie CT, Henderson PA, Yeap G-Y. Liquid crystal oligomers: going beyond dimers. Liq Cryst. 2009;36(6-7):755-777. 
[9] Panov VP, Nagaraj M, Vij JK, Panarin YP, Kohlmeier A, Tamba MG, Lewis RA, Mehl GH. Spontaneous Periodic Deformations in Nonchiral Planar-Aligned Bimesogens with a Nematic-Nematic Transition and a Negative Elastic Constant. Phys Rev Lett. 2010;105(16):167801.

[10] Sepelj M, Lesac A, Baumeister U, Diele S, Nguyen HL, Bruce DW. Intercalated liquid-crystalline phases formed by symmetric dimers with an alpha,omegadiiminoalkylene spacer. J Mater Chem. 2007;17(12):1154-1165.

[11] Abberley JP, Killah R, Walker R, Storey JMD, Imrie CT, Salamonczyk M, Zhu CH, Gorecka E, Pociecha D. Heliconical smectic phases formed by achiral molecules. Nature Communications. 2018;9:228.

[12] Salamonczyk M, Vaupotic N, Pociecha D, Walker R, Storey JMD, Imrie CT, Wang $\mathrm{C}$, Zhu CH, Gorecka E. Multi-level chirality in liquid crystals formed by achiral molecules. Nature Communications. 2019;10:1922.

[13] Sreenilayam SP, Panov VP, Vij JK, Shanker G. The N-TB phase in an achiral asymmetrical bent-core liquid crystal terminated with symmetric alkyl chains. Liq Cryst. 2017;44(1):244-253.

[14] Mandle RJ. Designing Liquid-Crystalline Oligomers to Exhibit Twist-Bend Modulated Nematic Phases. Chem Rec. 2018;18(9):1341-1349.

[15] Mandle RJ, Goodby JW. A Nanohelicoidal Nematic Liquid Crystal Formed by a Non-Linear Duplexed Hexamer. Angew Chem-Int Ed. 2018;57(24):7096-7100.

[16] Simpson FP, Mandle RJ, Moore JN, Goodby JW. Investigating the Cusp between the nano-and macro-sciences in supermolecular liquid-crystalline twist-bend nematogens. J Mater Chem C. 2017;5(21):5102-5110.

[17] Mandle RJ, Stevens MP, Goodby JW. Developments in liquid-crystalline dimers and oligomers. Liq Cryst. 2017;44(12-13):2046-2059.

[18] Jansze SM, Martinez-Felipe A, Storey JMD, Marcelis ATM, Imrie CT. A TwistBend Nematic Phase Driven by Hydrogen Bonding. Angew Chem Int Ed. 2015;54(2):643-646.

[19] Walker R, Pociecha D, Abberley JP, Martinez-Felipe A, Paterson DA, Forsyth E, Lawrence GB, Henderson PA, Storey JMD, Gorecka E, Imrie CT. Spontaneous chirality through mixing achiral components: a twist-bend nematic phase driven by hydrogen-bonding between unlike components. Chem Commun. 2018;54(27):33833386.

[20] Paterson DA, Crawford CA, Pociecha D, Walker R, Storey JMD, Gorecka E, Imrie $\mathrm{CT}$. The role of a terminal chain in promoting the twist-bend nematic phase: the synthesis and characterisation of the 1-(4-cyanobiphenyl-4 '-yl)-6-(4alkyloxyanilinebenzylidene-4 '-oxy)hexanes. Liq Cryst. 2018;45(13-15):2341-2351.

[21] Watanabe K, Tamura T, Kang SM, Tokita M. Twist bend nematic liquid crystals prepared by one-step condensation of 4-(4-Pentylcyclohexyl) benzoic acid and alkyl diol. Liq Cryst. 2018;45(6):924-930.

[22] Dawood AA, Grossel MC, Luckhurst GR, Richardson RM, Timimi BA, Wells NJ, Yousif YZ. Twist-bend nematics, liquid crystal dimers, structure-property relations. Liq Cryst. 2017;44(1):106-126.

[23] Panov VP, Vij JK, Mehl GH. Twist-bend nematic phase in cyanobiphenyls and difluoroterphenyls bimesogens. Liq Cryst. 2017;44(1):147-159.

[24] Paterson DA, Abberley JP, Harrison WT, Storey JM, Imrie CT. Cyanobiphenylbased liquid crystal dimers and the twist-bend nematic phase. Liq Cryst. 2017;44(1):127-146.

[25] Paterson DA, Xiang J, Singh G, Walker R, Agra-Kooijman DM, Martinez-Felipe A, Gan M, Storey JMD, Kumar S, Lavrentovich OD, Imrie CT. Reversible Isothermal Twist-Bend Nematic-Nematic Phase Transition Driven by the Photoisomerization of 
an Azobenzene-Based Nonsymmetric Liquid Crystal Dinner. J Am Chem Soc. 2016;138(16):5283-5289.

[26] Gorecka E, Vaupotic N, Zep A, Pociecha D, Yoshioka J, Yamamoto J, Takezoe H. A Twist-Bend Nematic (N-TB) Phase of Chiral Materials. Angew Chem-Int Ed. 2015;54(35):10155-10159.

[27] Walker R, Pociecha D, Strachan G, Storey JMD, Gorecka E, Imrie CT. Molecular curvature, specific intermolecular interactions and the twist-bend nematic phase: the synthesis and characterisation of the 1-(4-cyanobiphenyl-4'-yl)-6-(4alkylanilinebenzylidene-4'-oxy)hexanes (CB6O.m). Soft Matter. 2019;15:31883197.

[28] Greco C, Luckhurst GR, Ferrarini A. Molecular geometry, twist-bend nematic phase and unconventional elasticity: a generalised Maier-Saupe theory. Soft Matter. 2014;10(46):9318-9323.

[29] Dawood AA, Grossel MC, Luckhurst GR, Richardson RM, Timimi BA, Wells NJ, Yousif YZ. On the twist-bend nematic phase formed directly from the isotropic phase. Liq Cryst. 2016;43(1):2-12.

[30] Pociecha D, Crawford CA, Paterson DA, Storey JMD, Imrie CT, Vaupotic N, Gorecka E. Critical behavior of the optical birefringence at the nematic to twist-bend nematic phase transition. Phys Rev E. 2018;98(5):052706.

[31] Xiang J, Li YN, Li Q, Paterson DA, Storey JMD, Imrie CT, Lavrentovich OD. Electrically Tunable Selective Reflection of Light from Ultraviolet to Visible and Infrared by Heliconical Cholesterics. Adv Mater. 2015;27(19):3014-3018.

[32] Xiang J, Varanytsia A, Minkowski F, Paterson DA, Storey JMD, Imrie CT, Lavrentovich OD, Palffy-Muhoray P. Electrically tunable laser based on oblique heliconical cholesteric liquid crystal. Proc Natl Acad Sci USA. 2016;113(46):1292512928.

[33] Emsley JW, Luckhurst GR, Shilstone GN, Sage I. The preparation and properties of the $\alpha, \omega$-bis $(4,4$-cyanobiphenyloxy)alkanes - nematogenic molecules with a flexible core. Molec Cryst Liq Cryst. 1984;102(8-9):223-233.

[34] Luckhurst GR. Liquid crystals: a chemical physicist's view. Liq Cryst. 2005;32(1112):1335-1364.

[35] Arakawa Y, Komatsu K, Tsuji H. Twist-bend nematic liquid crystals based on thioether linkage. New J Chem. 2019;43:6786-6793.

[36] Frisch MJ, et al. Gaussian 09 (Revision B.01). Wallingford CT: Gaussian Inc.; 2010.

[37] Paterson DA, Abberley JP, Harrison WT, Storey JMD, Imrie CT. Cyanobiphenylbased liquid crystal dimers and the twist-bend nematic phase. Liq Cryst. 2017;44(1):127-146.

[38] Paterson DA, Gao M, Kim YK, Jamali A, Finley KL, Robles-Hernandez B, DiezBerart S, Salud J, de la Fuente MR, Timimi BA, Zimmermann H, Greco C, Ferrarini A, Storey JMD, Lopez DO, Lavrentovich OD, Luckhurst GR, Imrie CT. Understanding the twist-bend nematic phase: the characterisation of 1-(4cyanobiphenyl-4 '-yloxy)-6-(4-cyanobiphenyl-4 '-yl)hexane (CB6OCB) and comparison with CB7CB. Soft Matter. 2016;12(32):6827-6840.

[39] Paterson DA, Walker R, Abberley JP, Forestier J, Harrison WTA, Storey JMD, Pociecha D, Gorecka E, Imrie CT. Azobenzene-based liquid crystal dimers and the twist-bend nematic phase. Liq Cryst. 2017;44(12-13):2060-2078.

[40] Abberley JP, Jansze SM, Walker R, Paterson DA, Henderson PA, Marcelis ATM, Storey JMD, Imrie CT. Structure-property relationships in twist-bend nematogens: the influence of terminal groups. Liq Cryst. 2017;44(1):68-83.

[41] Emsley JW, De Luca G, Lesage A, Merlet D, Pileio G. The structure and conformation of a mesogenic compound between almost zero and almost complete orientational order. Liq Cryst. 2007;34(9):1071-1093. 
[42] Tarini M, Cignoni P, Montani C. Ambient Occlusion and Edge Cueing for Enhancing Real Time Molecular Visualization IEEE Trans Visualization and Computer Graphics. 2006;12(5):1237-1244.

[43] Zhu CH, Wang C, Young A, Liu F, Gunkel I, Chen D, Walba D, Maclennan J, Clark N, Hexemer A. Probing and Controlling Liquid Crystal Helical Nanofilaments. Nano Lett. 2015;15(5):3420-3424.

[44] Salamonczyk M, Mandle RJ, Makal A, Liebman-Pelaez A, Feng J, Goodby JW, Zhu $\mathrm{CH}$. Double helical structure of the twist-bend nematic phase investigated by resonant X-ray scattering at the carbon and sulfur K-edges. Soft Matter. 2018;14(48):9760-9763.

[45] Emerson APJ, Luckhurst GR. On the relative propensities of ether and methylene linkages for liquid-crystal formation in calamitics. Liq Cryst. 1991;10(6):861-868.

[46] Ferrarini A, Luckhurst GR, Nordio PL, Roskilly SJ. Prediction of the transitional properties of liquid-crystal dimers - a molecular-field calculation based on the surface tensor parametrization. J Chem Phys. 1994;100(2):1460-1469.

[47] Henderson PA, Niemeyer O, Imrie CT. Methylene-linked liquid crystal dimers. Liq Cryst. 2001;28(3):463-472.

[48] Henderson PA, Seddon JM, Imrie CT. Methylene- and ether-linked liquid crystal dimers II. Effects of mesogenic linking unit and terminal chain length. Liq Cryst. 2005;32(11-12):1499-1513.

[49] Henderson PA, Imrie CT. Methylene-linked liquid crystal dimers and the twist-bend nematic phase. Liq Cryst. 2011;38(11-12):1407-1414.

[50] Seed AJ, Toyne KJ, Goodby JW. Synthesis of some 2,4-disubstituted and 5,5disubstituted thiophene systems and the effect of the pattern of substitution on the refractive-indexes, optical anisotropies, polarizabilities and order parameters in comparison with those of the parent biphenyl and dithienyl systems. J Mater Chem. 1995;5(4):653-661.

[51] Attard GS, Date RW, Imrie CT, Luckhurst GR, Roskilly SJ, Seddon JM, Taylor L. Nonsymmetrical dimeric liquid-crystals - the preparation and properties of the $\alpha$-(4-

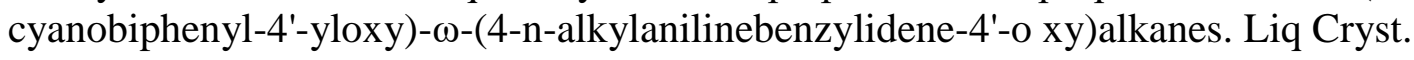
1994;16(4):529-581.

[52] Yeap GY, Osman F, Imrie CT. Non-symmetric dimers: effects of varying the mesogenic linking unit and terminal substituent. Liq Cryst. 2015;42(4):543-554.

[53] Li XD, Lee SK, Kang SM, Tokita M, Kawauchi S, Watanabe J. Effect of Alkylthio Tail on Phase Behaviors of Bent-shaped Molecules Based on Naphthalene Core. Chem Lett. 2009;38(5):424-425.

[54] Mason EA, Kreevoy MM. A simple model for barriers to internal rotation. J Am Chem Soc. 1955;77(22):5808-5814.

[55] Imrie CT, Karasz FE, Attard GS. Effect of backbone flexibility on the transitional properties of side-chain liquid-crystalline polymers. Macromolecules. 1993;26(15):3803-3810.

[56] Imrie CT, Karasz FE, Attard GS. Comparison of the mesogenic properties of monomeric, dimeric, and side-chain polymeric liquid-crystals. Macromolecules. 1993;26(3):545-550.

[57] Zong X, Fang Z, Wu C. Synthesis and mesomorphic properties of a series of dimers derived from thioether-terminated and cholesteryl. Liq Cryst. 2018;45(12):18441853.

[58] Arakawa Y, Sasaki Y, Haraguchi N, Itsuno S, Tsuji H. Synthesis, phase transitions and birefringence of novel liquid crystalline 1,4-phenylene bis(4-alkylthio benzoates) and insights into the cybotactic nematic behaviour. Liq Cryst. 2018;45(6):821-830. 
[59] Arakawa Y, Inui S, Tsuji H. Novel diphenylacetylene-based room-temperature liquid crystalline molecules with alkylthio groups, and investigation of the role for terminal alkyl chains in mesogenic incidence and tendency. Liq Cryst. 2018;45(6):811-820.

[60] Pal SK, Raghunathan VA, Kumar S. Phase transitions in novel disulphide-bridged alkoxycyanobiphenyl dimers. Liq Cryst. 2007;34(2):135-141.

[61] Lee HC, Lu ZB, Henderson PA, Achard MF, Mahmood WAK, Yeap GY, Imrie CT. Cholesteryl-based liquid crystal dimers containing a sulfur-sulfur link in the flexible spacer. Liq Cryst. 2012;39(2):259-268.

[62] Gauza S, Li J, Wu ST, Spadlo A, Dabrowski R, Tzeng YN, Cheng KL. High birefringence and high resistivity isothiocyanate-based nematic liquid crystal mixtures. Liq Cryst. 2005;32(8):1077-1085.

[63] Arakawa Y, Kang SM, Tsuji H, Watanabe J, Konishi G. The design of liquid crystalline bistolane-based materials with extremely high birefringence. RSC Adv. 2016;6(95):92845-92851.

[64] Meyer C, Luckhurst GR, Dozov I. The temperature dependence of the heliconical tilt angle in the twist-bend nematic phase of the odd dimer CB7CB. J Mater Chem C. 2015;3(2):318-328.

[65] To TBT, Sluckin TJ, Luckhurst GR. Molecular field theory for biaxial nematics formed from liquid crystal dimers and inhibited by the twist-bend nematic. Phys Chem Chem Phys. 2017;19(43):29321-29332. 